
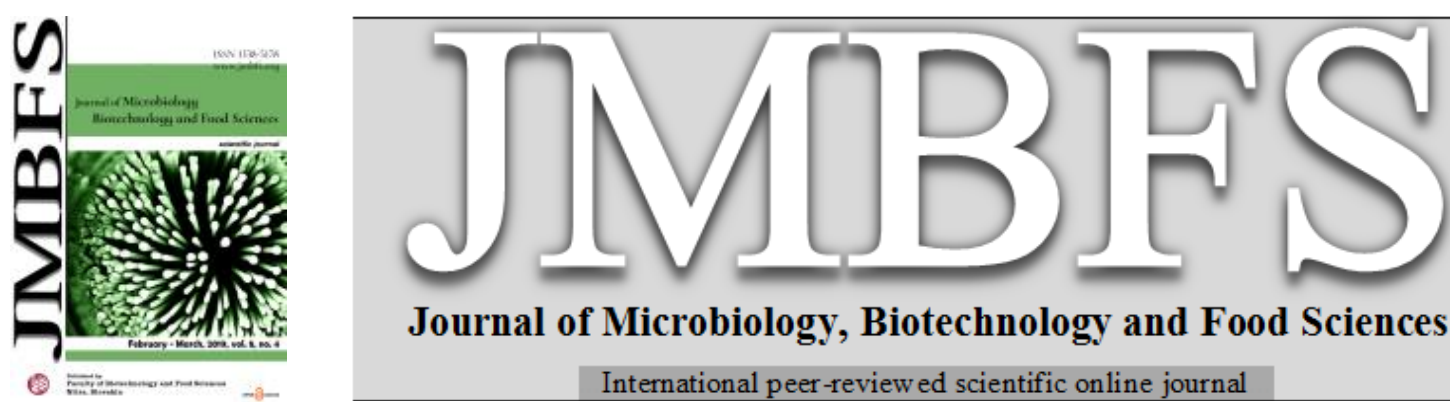

Journal of Microbiology, Biotechnology and Food Sciences

International peer-review ed scientific online journal

\title{
MARKER PROFILING OF WHEAT WITH DIFFERENT DROUGHT TOLERANCE BY CDDP
}

\author{
Matúš Kysel ${ }^{1}$, Jana Žiarovská ${ }^{1}$, Veronika Štefúnová ${ }^{1}$, Katarína Ražnál, Miroslav Švec ${ }^{2}$
}

Address(es): doc. Ing. PaedDr. Jana Žiarovská, PhD.,

${ }^{1}$ Slovak University of Agriculture in Nitra, Faculty of Agrobiology and Food Resources, Department of Genetics and Plant Breeding, Tr. A. Hlinku 2, 94976 Nitra, Slovakia.

${ }^{2}$ Comenius University, Bratislava, Faculty of Natural Sciences, Department of Genetics, Mlynská dolina, Ilkovičova 6, 84215 Bratislava 4, Slovakia.

*Corresponding author: jana.ziarovska@uniag.sk

doi: $10.15414 / j m b f s .2019 .8 .5 .1220-1222$

\section{ARTICLE INFO}

Received 31. 5. 2018

Revised 28. 10. 2018

Accepted 15. 1.2019

Published 1. 4. 2019

\section{Regular article}

open 2 access

\begin{abstract}
Wheat is considered to be the world oldest and most widely grown plant. Current genetic and genomic information about wheat is extensive and contains partial knowledge of various types of markers up to the genomic sequence data. Up to date, several different types of DNA markers have been used in the mapping of the wheat genome, that were used to describe the whole genome polymorphism of various wheat varieties. In study, CDDP markers were used to analyse the length polymorphism in the genome of two drought tolerant wheat varieties and two drought susceptible wheat varieties. Polymorphism has not been obtained in relation to the type of drought resistance in the analyzed wheat varieties in the summary of the CDDP profiles. The primer combination WRKY-F and WRKY$\mathrm{R} 1$ has one fragment with a constant amplicon length of $129 \mathrm{bp}$ in all the analyzed varieties. For the combination of WRKY-F and WRKY-R2, the length of the amplicon shifted to $129-130$ bp and to the 130-132 bp by F/R3 combination. The combinations of WRKYF and WRKY-R2b and WRKY-F and WRKY-R3b with the exception of the Dagmar variety (WRKY-F and WRKY-2b) did not amplify amplicons of the given size. For the F/R1 primer combination, the fragments 301-304 bp, 138-140 bp and 187-192 bp were also typical. The second primer combination (WRKY-F and WRKY-R2) has generated fragments of the length of 156-158 bp and 181-186 bp in addition to the 129-130 bp fragment in all varieties. All are nonspecific. The marker system provides monomorphic profiles in all analyzed varieties and the total number of detected fragments was 81
\end{abstract}

Keywords: CDDP, wheat, BARE-1, drought, polymorphism

\section{INTRODUCTION}

Wheat is one of the most widely used basic food stuff in the world. It grows on more than 218.000 .000 hectares, and is consumed by 2.5 billion people in approximately 89 countries. Its agronomic adaptability has resulted in an extensive production in almost all parts of the world and wheat trade is larger than all other crops combined together. Wheat offers easy storage and is used by many ways in food production. It is a great source of carbohydrates and proteins. Wheat is considered to be the world oldest and most widely grown plant. The beginnings of cultivation coincide with the period of the emergence of agriculture in $10-8$ thousand years B.C. and up to 25.000 different cultivars of wheat are grown at present (Gustafson et al. 2009).

Current genetic and genomic information about wheat is extensive and contains partial knowledge of various types of markers up to the genomic sequence data Genome research of wheat is considerably complicated due to its genome complexity and size, which is about $17 \mathrm{~Gb}$ in the case of hexaploids and combined with the fact that each individual chromosome of wheat has a size in the range of 605 - $995 \mathrm{Mb}$ (Doležel et al. 2009).

Up to date, several different types of DNA markers have been used in the mapping of the wheat genome, that were used to describe the whole genome polymorphism of various wheat varieties (Kaffeel, 2014, Kut'ka Hlozáková $\boldsymbol{e}$ al. 2016) or mapping studies of different types of resistance (Kaur $\boldsymbol{e t}$ al. 2008). Marker based studies aimed to the drought tolerance are applied as well. Wei $\boldsymbol{e}$ al. (2009) has used DNA markers for mapping analysis of drought candidate genes DREB1 and DREB2 and CAPS markers were chosen to map DREB3 and CBF genes (Miller et al. 2006).

Ashraf et al. (2010) reported that the use of four conventional marker systems AFLP, RFLP, SSR and ISSR are suitable to analyze the polymorphism among parental genotypes and F2 generation of twelve wheat genotypes. This study has developed the DNA resistance markers based on 38 RAPD primers, 25 ISSR primers and 46 SSR primers, which can be used in the breeding programs as a selection tool. The mapping of drought QTL loci has been applied up to date in many crops such as maize, wheat, barley, cotton, sorghum and rice (Quarrie $\boldsymbol{e} t$ al. 1994; Teulat et al. 2008, Sari-Gorla et al. 1999, Sanchez et al. 2002, Bernier et al. 2008).

Here, CDDP markers were used to analyse the length polymorphism in the genome of two drought tolerant wheat varieties and two drought susceptible wheat varieties.

\section{MATERIAL AND METHODS}

The biological material used for the analysis consisted from wheat varieties Venturero and Seladon (drought tolerant) and varieties Aladin and Dagmar (drought susceptible). Total genomic DNA was extracted from young leaves following the method of Rogers and Bendich (1994). Markers based on conserved regions of DNA or gene families represent a group of gene-specific marker systems including techniques PBA and CDDP (Tab 1). Primers are here derived from protein sequences of well characterized genes. GC pair's content by CDDP primers exceeded $60 \%$ (Xie et al. 2005). The letter "S" denotes the presence of a $\mathrm{C}$ or $\mathrm{G}$ base. PBA primers were again designed using human cytochrome $\mathrm{P} 450$ sequences (Inui et al. 2000).

Table 1 List of CDDP primers utilized for this analysis

\begin{tabular}{|c|c|c|c|}
\hline Primer & Sequence & Marker system & $\begin{array}{l}\text { Length } \\
\text { (bp) }\end{array}$ \\
\hline WRKY-R1 & $\begin{array}{l}5^{\prime}- \\
\text { GTGGTTGTGCTTGCC }\end{array}$ & CDDP & 15 \\
\hline WRKY-R2 & 5'-GCCCTCGTASGTSGT & CDDP & 15 \\
\hline WRKY-R2B & 5'-TGSTGSATGCTCCCG & CDDP & 15 \\
\hline WRKY-R3 & $\begin{array}{l}5^{\prime}- \\
\text { GCASGTGTGCTCGCC }\end{array}$ & CDDP & 15 \\
\hline WRKY-R3B & $\begin{array}{l}5^{\prime}- \\
\text { CCGCTCGTGTGSACG }\end{array}$ & CDDP & 15 \\
\hline
\end{tabular}

Legend: $\mathrm{G}$ - guanine, $\mathrm{T}$ - thymine, $\mathrm{C}$ - cytosine, $\mathrm{A}$ - adenine, $\mathrm{S}$ - strong $(\mathrm{G}$ or C) 
PCR amplification was performed by 2x MyTaq polymerase (Bioline) 600 $\mathrm{nM} \cdot \mathrm{dm}^{-1}$ of primers and using of $50 \mathrm{ng}$ of DNA. Amplification reactions were performed in $\mathrm{C} 1000$ thermocycler (BioRad) with following temperature and time profile: $95^{\circ} \mathrm{C}, 5$ minutes $\left(95^{\circ} \mathrm{C}, 60 \mathrm{sec} ; 50^{\circ} \mathrm{C}, 60 \mathrm{sec} ; 72^{\circ} \mathrm{C}, 120 \mathrm{sec}\right) 45$ times plus $72^{\circ} \mathrm{C} 10$ minutes final elongation. Amplified fragments were separated in $2 \%$ agarose gels stained by GelRed (Biotium) and analyzed online by GelAnalyser.

\section{RESULTS AND DISCUSSION}

CDDP marker system has generated in the genome of Venturero variety the DNA fragments that were depended on the used reverse primers. The combination of primers WRKY-F and WRKY-R2 amplified fragments of the length of 227-228 bp. The largest fragment among all primer combinations in this variety is the 387 bp fragment obtained in the forward combination of WRKY-F and WRKY-R3, but it can not be considered as variety or primer specific. Amplicon of the length $151-160 \mathrm{bp}$ is the only fragment that is present in all primer combinations, and thus can be included among the nonspecific amplicons obtained in the CDDP analysis. In addition, fragments of the length of 129-132 bp (WRKY-R1, WRKY-R2 and WRKY-R3), 182-187 bp (WRKY-R1, WRKY-R2 and WRKY R2b) and 227-228 bp (WRKY-R2 and WRKY-R2b) were also amplified in the Venturero variety. Reverse primers WRKY-R2b and WRKY-R3b gave only three fragments to amplify.

The Seladon variety resembles Venturero in the obtained CDDP profile, because fragments of the maximum length (375 bp, figure 1a) were amplified in the primer combination of WRKY-F and WRKY-R3 and the minimum length in the forward combination of WRKY-F and WRKY-R2. Another common feature is the variety nonspecific fragments of lengths of 155-159 bp present in all prime combinations and potentially specific fragments of WRKY-R1, WRKY-R2 and WRKY-R3 reverse primers (129-131 bp) and WRKY-R1, WRKY-R2 and WRKY-R2b reverse primers (182-187 bp). The difference between Seladon and Venturero is the replacement of the amplified fragments generated by WRKY-R2 and WRKY-R2b in the Venturero variety with a length of 215-216 bp (WRKY R3 and WRKY-R3b). The least abundant primer combinations in the Seladon variety were WRKY-F/ WRKY-R2 and WRKY-F/WRKY-R2b.

Nor the Dagmar variety differs from the previous two varieties from the perspective of the obtained CDDP profile. The longest amplified fragment has a length of $383 \mathrm{bp}$ (figure 1a). What has been observed in the Seladon variety with connection to nonspecific and primer-specific fragments is also applicable to the Dagmar variety. Fragments of the length of $152-158$ bp are variety nonspecific as well as fragments 129-132 bp (WRKY-R1, WRKY-R2, WRKY-R3 and WRKYR2b), 181-189 bp (WRKY-R1, WRKY-R2 and WRKY-R2b) and 212-219 bp (WRKY-R3 and WRKY-R3b). Fragments of the length of 129-132 bp could be considered nonspecific for the Dagmar variety, although they are absent in the primer combination of WRKY-F and WRKY-R3b. The primer combination where the least fragments were obtained is WRKY-F and WRKY-R2. The number of fragments in each profile has increased slightly in the Dagmar variety. When comparing the Aladin variety with others, it was observed that the fragment of primer combinations WRKY-F and WRKY-R3 with a length of 364 bp (figure 1b) and the primer combination WRKY-F and WRKY-R2 with a generated amplicon of the length of $186 \mathrm{bp}$ fragments point to the primer-specific fragments of the CDDP marker system when used in the analyzed wheat accessions. Conversely, nonspecific fragment of the length of 152-159 bp does not appear in all primer combinations (absence at the WRKY-R1). Also, the primer specific fragment of 214-219 bp occurred in addition to the primer combination WRKY-F and WRKY-R3b also at the WRKY-R2b reverse primer, and was not observed in any other primer combination. Fragments of the size of 129-130 bp (WRKY-R1, WRKY-R2 and WRKY-R3) and 181-192 bp (WRKYR1, WRKY-R2 and WRKY-R2b) confirmed their potential of primer specific amplicons.

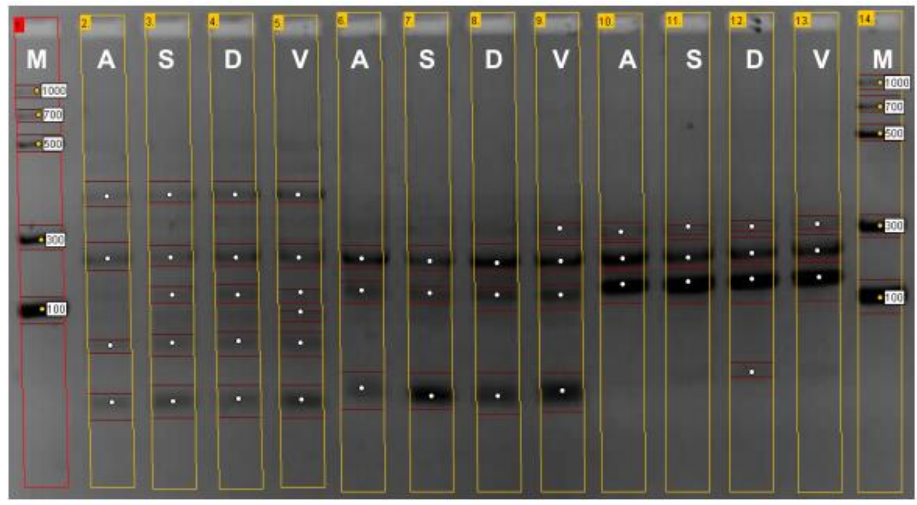

Figure 1a Amplicons generated by CDDP for analyzed wheat varieties. M ladder, A-Aladin WRKYF+R1, S-Seladon WRKY-F/ WRKY-R1, D-Dagmar WRKY-F/ WRKY-R1, V-Venturero WRKY-F/ WRKY-R1; A-Aladin WRKY-F/ WRKY-R2，S-Seladon WRKY-F/ WRKY-R2，D-Dagmar WRKY-
F/ WRKY-R2, V-Venturero WRKY-F/ WRKY-R2; M - Ladder; A-Aladin WRKY-F/ WRKY-R2b, S-Seladon WRKY-F/ WRKY-R2b, D-Dagmar WRKY-F/ WRKY-R2b, V-Venturero WRKY-F/ WRKY-R2b

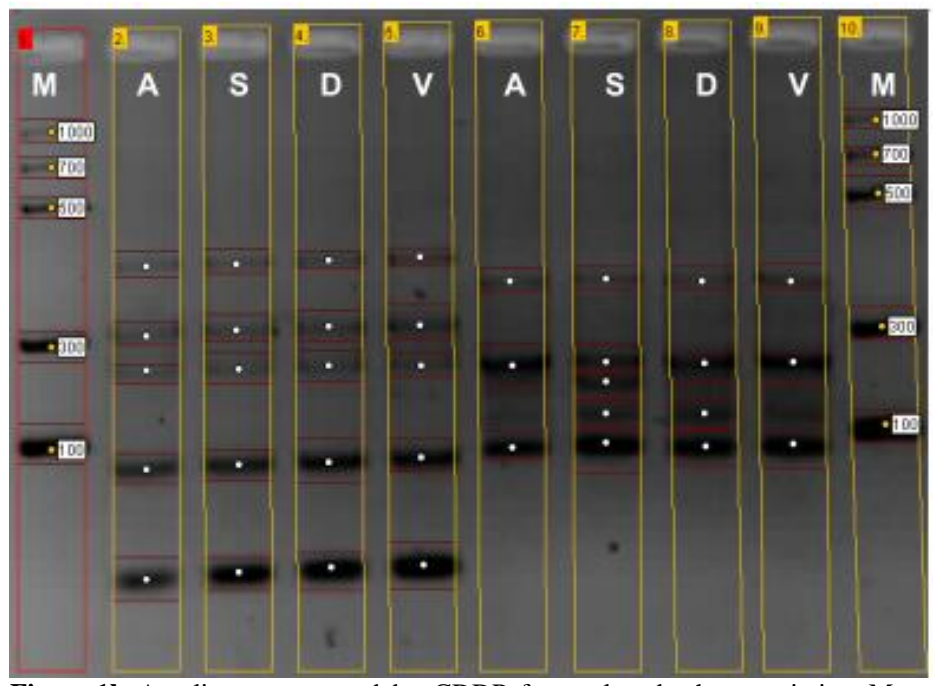

Figure 1b Amplicons generated by CDDP for analyzed wheat varieties. M ladder, A-Aladin WRKY-F/ WRKY-R3, S-Seladon WRKY-F/ WRKY-R3, DDagmar WRKY-F/ WRKY-R3, V-Venturero WRKY-F/ WRKY-R3;. A-Aladin WRKY-F/ WRKY-R3b, S-Seladon WRKY-F/ WRKY-R3b, D-Dagmar WRKYF/ WRKY-R3b, V-Venturero WRKY-F/ WRKY-R3b; M - ladder

It can be concluded that the polymorphism has not been obtained in relation to the type of drought resistance in the analyzed wheat varieties in the summary of the CDDP profiles. The primer combination WRKY-F/ WRKY-R1 has one fragment with a constant amplicon length of $129 \mathrm{bp}$ in all the analyzed varieties. For the combination of WRKY-F/ WRKY-R2, the length of the amplicon shifted to $129-130 \mathrm{bp}$ and to the 130-132 bp by WRKY-F/ WRKY-R3 combination. The combinations of WRKY-F/ WRKY-R2b and WRKY-F/ WRKY-R3b with the exception of the Dagmar variety (WRKY-F/ WRKY- 2b) did not amplify amplicons of the given size. For the F/R1 primer combination, the fragments 301 $304 \mathrm{bp}, 138-140 \mathrm{bp}$ and $187-192 \mathrm{bp}$ were also typical. The second primer combination (WRKY-F/ WRKY-R2) has generated fragments of the length of $156-158 \mathrm{bp}$ and 181-186 bp in addition to the 129-130 bp fragment in all varieties. All are nonspecific. The WRKY-R2b reverse primer provided a similar output, 3-4 fragments per variety with a maximum length of $228 \mathrm{bp}$. This fragment is specific for the primer combination WRKY-F/ WRKY-R2b, unlike the primer combination WRKY-F/ WRKY-R2. The absence of this fragment in the Aladin variety is not so significant as to affect the specificity (the presence of a 219 bp fragment in the Aladin variety). Primer combination with reverse primer WRKY-R3 has generated constant 5 fragments for each variety. The previous text shows that this combination provided the largest fragments and two potential primer-specific fragments are presented here. Both of them (257-261 bp and 215$219 \mathrm{bp}$ ) are absent in the Aladin variety, but the second one also occurs when combined with the modified reverse primer WRKY-R3b (212-216 bp). In both combinations there are nonspecific fragments of the length 158-160 bp and 181186 bp (combination WRKY-F/ WRKY-R2b) and 130-132 bp and 152-157 bp (combination WRKY-F/ WRKY-R3). The CDDP profile with the highest number of amplified fragments was obtained by combining with reverse primer WRKY R3. Modified reverse primer WRKY-R3b gave weaker amplification because only three fragments, a fragment of $328 \mathrm{bp}$ with only Seladon and Aladin, the only fragment of Venturero and Aladin, the 151-158 bp fragment did not provide the necessary specificity, and the $212-216 \mathrm{bp}$ fragment only provided specificity in primer combinations WRKY-F/ WRKY-R3 and WRKY-F/ WRKY-R3b. In case of analysis of summer wheat varieties by CDDP markers, the following can be summarized. The marker system provides monomorphic profiles in all analyzed varieties and the total number of detected fragments was 81 , which is relatively small for the four varieties analyzed and the five primer combinations.

Universal and degenerate short primers derived from functional genes such as Homeobox Genes (KNOX), Transcription Factors Contributing to Developmental and Physiological Processes (WRKY), Transcription Factors Activated in Response to Biotic and Abiotic Stress (MYB), Induction and Development Control Genes (MADS) or Auxine Binding Protein (ABP1) genes with high levels of polymorphisms of their conserved domains (Anai et al. 1997; Nagasaki et al. 2001; Stracke et al. 2004; Xie et al. 2005) were applied to the new CDDP marker system by Collard and Mackill (2009a). However, the conservatively of the binding sites for the primers differs due to biotic and abiotic stress or distributional development, which may serve to identify quantitative locus loci in mapping candidate genes. The typical CDDP fragment profile ranges from 200-1,500 bp than with RAPD but is reproducible. Reproducibility increases with the use of a single long prolongation prolonged at high Ta despite 
the fact that it can not always be ensured (Poczai et al. 2013). This primer acts as primer $\mathrm{F}$ and combines most often with RAPD or ISSR primers (Gupta $\boldsymbol{e t}$ al. 1994). Previous ScoT studies have shown that reproducibility decreases significantly when the GC fraction falls below 60\% (Collard and Mackill, 2009b) and therefore such combinations do not produce consistent results with CDDP (Collard and Mackill, 2009a). Primers are of 15-19 bases in length with more than $60 \%$ GC and 3 inoculated nucleotides and their development depends on the number of allelic variants in the genomic databases of the respective species to identify all suitable ecological and agronomic genes (Poczai et al 2011). 12 primers from twenty primary combinations, including WRKY-F/ WRKY-R2 and WRKY-F/ WRKY-R3b combinations, which Collard and Mackill (2009a) tested 54 polymorphic markers of rice, together with information obtained by taxonomic and pedigree analysis, used 10 radar genotypes to assemble the radial tree. Li et al. (2013) reached 19 CDDP primers that generated 241 fragments of these 223 polymorphic. The authors agreed that only 2 primary combinations (WRKY-F/ WRKY-R2 and WRKY-F/ WRKY-R3) are sufficient to recognize all 53 records. Adawy et al., (2014) compared different marker techniques and have found them equally effective and appropriate for the type of study with adequate polymorphism (100\% CDDP primer combinations WRKY-F/ WRKY-R2 and WRKY-F/ WRKY-R3, 10 polymorphic fragments out of a total of 30 on each).

\section{CONCLUSION}

Analysis of the length polymorphism of the CDDP profiles was analysed in the study and a variability of obtained amplicons was described. Four wheat varieties were used in the study - Aladin, Seladon, Dagmara and Venturero. All the obtained CDDP were compared and specific polymorphism was detected among the analysed wheat varieties, but this was not in the relationship toward the drought tolerance.

Acknowledgments: This research was supported by APVV-15-0156 Genomická selekcia obilnín na suchovzdornost'.

\section{REFERENCES}

ADAWY, S., ATIA, M.A.M. 2014. A multidisciplinary molecular marker approaches to assess the genetic diversity in Egyptian date palm. International Journal of Bio-Technology and Research, 4(6), 1-12

ANAI, T., MIYATA, M., KOSEMURA, S., YAMAMURA, S., TSUGE, T., MATSUI, M., UCHIA, H., HASEGAWA, K. 1997. Comparison of abp1 primary sequences from monocotyledonous and dicotyledonous species. Journal of Plant Physiology, 151(4), 446-449. https://doi.org/10.1016/S01761617(97)80010-7.

ASHRAF, M. 2010. Inducing drought tolerance in plants: recent advances. $\begin{array}{lll}\text { Biotechnology Advances, } & \text { 28(1), }\end{array}$ https://doi.org/10.1016/j.biotechadv.2009.11.005.

BERNIER, J., ATLIN, G. N., SERRAJ, R., KUMAR, A., SPANER, D. 2008 Breeding upland rice for drought resistance. Journal of the Science of Food and Agriculture, 88(6), 927-939. https://doi.org/10.1002/jsfa.3153.

COLLARD, B. C. Y., MACKILL, D. J. 2009a. Conserved DNA-derived polymorphism (CDDP): a simple and novel method for generating DNA markers in plants. Plant Molecular Biology Reporter, 27(4), 558 https://doi.org/10.1007/s11105-009-0118-Z.

COLLARD, B. C. Y., MACKILL, D. J. 2009b. Start codon targeted (SCoT) polymorphism: a simple, novel DNA marker technique for generating genetargeted markers in plants. Plant Molecular Biology Reporter, 27(1), 86. https://doi.org/10.1007/s11105-008-0060-5.

DOLEŽEL, J., ŠIMKOVÁ, H., KUBALÁKOVÁ, M., Š́AFÁR̆, J., SUCHÁNKOVÁ, P., ČÍHALÍKOVÁ, J., BARTOŠ, J., VALÁRIK, M. 2009. Chromosome genomics in Triticeae. In Feuillet, C., Muehlbauer, G. J. (eds): Genetics and genomics of the Triticeae. Springer, New York, ISBN 285-316. https://doi.org/10.1007/978-0-387-77489-3_10

GUPTA, M., CHYI, Y. S., ROMERO-SEVERSON, J., OWEN, J. L. 1994 Amplification of DNA markers from evolutionarily diverse genomes using single primers of simple-sequence repeats. Theoretical and Applied Genetics, 89(7), 998-1006. https://doi.org/10.1007/BF00224530.

GUSTAFSON, P., RASKINA, O., MA, X., NEVO, E. 2009. Wheat evolution, domestication, and improvement. In B. F. Carver (ed) Wheat Science and Trade. pp. 5-30, Iowa. Wiley-Blackwell. http://scholar.googleusercontent.com/scholar?q=cache:-

JwxTcxbCqQJ:scholar.google.com/+Wheat+evolution,+domestication,+and+imp rovement\&hl=sk\&as_sdt $=0,5 \&$ as_vis $=1$.

INUI, H., KODAMA, T., OHKAWA, Y., OHKAWA, H. 2000. Herbicide metabolism and cross-tolerance in transgenic potato plants co-expressing human CYP1A1, CYP2B6, and CYP2C19. Pesticide Biochememistry and Physiology, 66(2), 116-129. https://doi.org/10.1006/pest.1999.2454.

KAFEEL, AHMAD. 2014. RAPD and SSR Based Genetic Diversity Analysis of Elite-2 Set of Synthetic Hexaploid Wheats. African Journal of Traditional,
Complementary and Alternative Medicines [online], 11(4), 9-13 [cit. 2017-12 18]. https://www.ncbi.nlm.nih.gov/pmc/articles/PMC4202390/.

KAUR, N., STREET, K., MACKAY, M., YAHIAOUI, N., KELLER, B. 2008 Molecular approaches for characterization and use of natural resistance in wheat European Journal of Plant Pathology, 121(3), 387-397. https://doi.org/10.1007/s10658-007-9252-3.

KUŤKA HLOZÁKOVÁ, T., GREGOVÁ, E., VIVODÍK, M., GÁlOVÁ, Z 2016. Genetic diversity of European cultivars of common wheat (Triticum aestivum L.) based on RAPD and protein markers. Journal of Central European Agriculture, 17 (4) p. 957-969 https://doi.org//10.5513/JCEA01/17.4.1798

LI, T., LI, Y., NING, H., SUN, X., ZHENG, C. 2013. Genetic diversity assessment of chrysanthemum germplasm using conserved DNA-derived polymorphism markers. Scientia Horticulturae 162, 271-277. https://doi.org/10.1016/j.scienta.2013.08.027.

MILLER, A. K., GALIBA, G., DUBCOVSKY, J. 2006. A cluster of 11 CBF transcription factors is located at the frost tolerance locus Fr-Am2 in Triticum monococcum. Molecular Genetics and Genomics, 275(2), 193-203. https://doi.org/10.1007/s00438-005-0076-6.

NAGASAKI, H., SAKAMOTO, T., SATO, Y., MATSUOKA, M. 2001 Functional analysis of the conserved domains of a rice KNOX homeodomain protein, OSH15. Plant Cell, 13(9), 2085-2098 https://doi.org/10.1105/TPC.010113.

POCZAI, P., VARGA, I., BELL, N. E., HYVÖNEN, J. 2011. Genetic diversity assessment of bittersweet (Solanum dulcamara, Solanaceae) germplasm using conserved DNA-derived polymorphism and intron-targeting markers. Annals of Applied Biology, 159(1): 141-153. https://doi.org/10.1111/j.1744 7348.2011.00482.x

POCZAI, P., VARGA, I., LAOS, M., CSEH, A., BELL, N., VALKONEN, J. P., HYVÖNEN, J. 2013. Advances in plant gene-targeted and functional markers: a review. Plant Methods, 9(1), 6. https://doi.org/10.1186/1746-4811-9-6.

QUARRIE, S. A., GULLI, M., CALESTANI, C., STEED, A., MARMIROLI, N. 1994. Location of a gene regulating drought-induced abscisic acid production on the long arm of chromosome 5A of wheat. Theoretical and Applied Genetics, 89(6), 794-800. https://doi.org/10.1007/BF00223721.

ROGERS, S. O. - BENDICH, A. J.. 1994. Extraction of total cellular DNA from plants, algae and fungi. Plant Molecular Biology Manual, Springer Netherlands, 183-190. https://doi.org/10.1007/978-94-011-0511-8_12.

SANCHEZ, A. C., SUBUDHI, P. K., ROSENOW, D. T., NGUYEN, H. T. 2002 Mapping QTLs associated with drought resistance in sorghum (Sorghum bicolor L. Moench). Plant Molecular Biology, 48(5-6), 713-726. https://doi.org/10.1023/A:1014894130270.

SARI-GORLA, M., KRAJEWSKI, P., DI FONZO, N., VILLA, M., FROVA, C 1999. Genetic analysis of drought tolerance in maize by molecular markers. II. Plant height and flowering. Theoretical and Applied Genetics, 99(1-2), 289-295. https://doi.org/10.1007/s001220051234.

STRACKE, R., WERBER, M., WEISSHAAR, B. 2001. The R2R3-MYB gene family in Arabidopsis thaliana. Current Opinion in Plant Biology, 4(5), 447-456. https://doi.org/10.1016/S1369-5266(00)00199-0.

TEULAT, B., MONNEVEUX, P., WERY, J., BORRIES, C., SOUYRIS, I., CHARRIER, A., THIS, D. 2008. Relationships between relative water content and growth parameters under water stress in barley: a QTL study. New Phytologist, 137(1), 99-107. https://doi.org/10.1046/j.1469-8137.1997.00815.x.

WEI, B., JING, R., WANG, C., CHEN, J., MAO, X., CHANG, X., JIA, J. 2009 Dreb1 genes in wheat (Triticum aestivum L.): development of functional markers and gene mapping based on SNPs. Molecular Breeding, 23(1), 13-22. https://doi.org/10.1007/s11032-008-9209-z.

XIE, Z., ZHANG, Z. L., ZOU, X., HUANG, J., RUAS, P., THOMPSON, D. SHEN, Q. J. 2005. Annotations and functional analyses of the rice WRKY gene superfamily reveal positive and negative regulators of abscisic acid signaling in aleurone cells. Plant Physiology, 137(1), 176-189. https://doi.org/10.1104/pp.104.054312. 